International Journal of Remote Sensing

Vol. 28, No. 24, 20 December 2007, 5447-5459

\title{
Land-cover classification in the Brazilian Amazon with the integration of Landsat ETM+ and Radarsat data
}

\section{LU* ${ }^{*} \S, M$. BATISTELLA + and E. MORAN $\uparrow \S$}

$\dagger$ Center for the Study of Institutions, Population, and Environmental Change (CIPEC), Indiana University, Bloomington, Indiana, 47408, USA

$\ddagger$ Brazilian Agricultural Research Corporation, Embrapa Satellite Monitoring, Campinas, São Paulo, 13088, Brazil

§Anthropological Center for Training and Research on Global Environmental Change (ACT), Indiana University, Bloomington, Indiana, 47405, USA

(Received 9 September 2005; in final form 19 November 2006)

\begin{abstract}
Land-cover classification with remotely sensed data in moist tropical regions is a challenge due to the complex biophysical conditions. This paper explores techniques to improve land-cover classification accuracy through a comparative analysis of different combinations of spectral signatures and textures from Landsat Enhanced Thematic Mapper Plus (ETM+) and Radarsat data. A wavelet-merging technique was used to integrate Landsat ETM + multispectral and panchromatic data or Radarsat data. Grey-level co-occurrence matrix (GLCM) textures based on Landsat ETM + panchromatic or Radarsat data and different sizes of moving windows were examined. A maximum-likelihood classifier was used to implement image classification for different combinations. This research indicates the important role of textures in improving land-cover classification accuracies in Amazonian environments. The incorporation of data fusion and textures increases classification accuracy by approximately $5.8-6.9 \%$ compared to Landsat ETM+ data, but data fusion of Landsat ETM+ multispectral and panchromatic data or Radarsat data cannot effectively improve land-cover classification accuracies.
\end{abstract}

\section{Introduction}

Accurate image classification describing spatial distribution and patterns of land cover is a prerequisite for many research topics and applications, such as landscape characterization, land-cover change analysis, input into different models for analysis of carbon cycles, habitat suitability and risk of land degradation. Many efforts and progresses have been made to improve the land-cover or vegetation classification performance, for example, use of subpixel information based on spectral mixture analyses (Adams et al. 1995, Roberts et al. 1998, Lu et al. 2003b), use of nonparametric classifiers such as neural networks (Paola and Schowengerdt 1995, Atkinson and Tatnall 1997, Kavzoglu and Mather 2004) and decision trees (Friedl and Brodley 1997, Pal and Mather 2003) and use of parameters derived from forest structures such as vegetation age or biomass (Foody et al. 1996, Vieira et al. 2003,

*Corresponding author. Dengsheng $\mathbf{L u}$, School of Forestry and Wildlife Sciences, Auburn University, 602 Duncan Drive, Auburn, AL 36849, USA. Email: DZL0001@ auburn.edu

International Joumal of Remote Sensing

ISSN 0143-1161 priaviISSN 1366-5901 online (C) 2007 Taylor \& Francis

http://www.tandf.co.uk/journals

DOI: $10.1080 / 01431160701227596$ 
Lu 2005). However, the landscape complexity in colonization frontiers and the abundant tree species of the Amazonian forests often impair the separation of landcover classes when using remotely sensed data, especially the distinctions between (1) successional vegetation stages and (2) successional vegetation and agroforestry. Although several works have explored different approaches to classify successional vegetation stages (Mausel et al. 1993, Moran et al. 1994, Brondízio et al. 1996, Foody et al. 1996, Steininger 1996, Rignot et al. 1997, Yanasse et al. 1997, Lucas et al. 2002, Lu et al. 2003a, Vieira et al. 2003, Lu 2005), the accuracy achieved is still poor. The main difficulties stem from the continuous transition of successional vegetation stages and the similar stand structures between successional stages and agroforestry, or between the initial successional stage and degraded pasture. To date, remote-sensing approaches to effectively separate these classes have not been developed. Because of the recognized importance of successional vegetation and agroforestry systems in providing environmental services such as carbon sequestration and restoration of degraded lands, more accurate classifications will reduce uncertainties in models and evaluations using such information.

Most previous research uses single-sensor data only for land-cover classification, but rarely has research explored the integration of different sensor data to improve classification accuracy in the moist tropical regions. The different characteristics of optical and radar data may provide new insights for such a task. We assume that (1) incorporation of different spatial and spectral resolution data (e.g. Landsat Enhanced Thematic Mapper Plus (ETM+) multispectral and panchromatic data, Radarsat data), (2) combination of spectral signatures and textures and (3) combination of data fusion and textures may improve the results. Hence, this paper aims to identify a suitable image processing procedure for improving land-cover classification accuracy through a comparative analysis of different image combinations based on Landsat ETM+ and Radarsat data.

\section{Study area}

The state of Rondônia has experienced high deforestation rates since the 1970s (INPE 2002). Following the national strategy of regional occupation and development, colonization projects initiated by the Brazilian government played a major role in this process (Batistella et al. 2003). Most colonization projects in the state were designed to settle landless migrants. The immigrants have transformed the forested landscape into a mosaic of cultivated crops, pastures, and different stages of secondary succession and forest remnants. The study area is located at Machadinho d'Oeste in northeastern Rondônia. Settlement began in the mid-1980s, and since then land-use/cover trajectories following deforestation have put in place a dynamic process of forest fragmentation. A well-defined dry season lasts from June to August, the annual average precipitation is $2016 \mathrm{~mm}$, and the annual average temperature is $25.5^{\circ} \mathrm{C}$ (Rondônia 1998). Batistella (2001) describes in detail the characteristics of this location, a landscape in transition from a matrix dominated by forest to land covers with lower carbon content.

3. Method

\subsection{Land-cover classification scheme}

A suitable classification scheme is critical for land-cover classification using remotely sensed data and for field data collection. Based on our previous experience 
in the region (e.g. Mausel et al. 1993, Brondizio et al. 1996, Lu et al. 2004), the requirement of subclasses of secondary succession for Amazonian research, and the importance of coffee plantations in this study area (Batistella and Moran 2005), we defined 12 classes to be mapped. Our previous research has indicated that three stages - initial (SS1), intermediate (SS2), and advanced (SS3) secondary succession - are suitable for most study areas (Brondízio et al. 1996, Lu et al. 2003a). Successional vegetation is assigned solely to areas where the grass cover is less than $25 \%$, which generally occurs in sites that have been abandoned for more than two years. The separation of different successional stages is based on the vegetation stand structures, that is, average diameter at breast height (DBH), canopy height, and biomass (Lu et al. 2003a). The primary forest is separated into upland forest (UPF) and lowland forest (LLF) based on moist conditions and topographic factors.

In the initial few years after deforestation, the land is often used for annual crops and cattle ranching. Pasture lands are classified as cultivated pasture (CUP) and degraded pasture (DGP) based on land management and land cover. That is, cultivated pastures are defined as areas with grass cover greater than $75 \%$, and degraded pastures are defined as areas with grass cover between $25 \%$ and $75 \%$. Agroforestry (AGF) systems in the study area are productive arrangements that include economic tree species, coffee, cocoa and other understory species. Coffee plantations (CFP) are separated. Other land-cover classes include infrastructure (urban areas and roads), water and non-vegetation lowland (NVL).

\subsection{Field data collection}

Fieldwork was conducted during the dry seasons of 1999, 2000, 2002 and 2003. Vegetation surveys were conducted in areas with relatively homogeneous ecological conditions (i.e. topography, distance from water and land use). After defining the area to be surveyed (plot sample), three subplots including nested parcels of $1 \mathrm{~m}^{2}$, $9 \mathrm{~m}^{2}$ and $100 \mathrm{~m}^{2}$ (small, medium, large, respectively) were randomly selected to accurately represent the variability within the plot sample. Seedlings were defined as young trees or shrubs with a stem diameter smaller than $2 \mathrm{~cm}$. Saplings were defined as young trees with a stem DBH greater than $2 \mathrm{~cm}$ and smaller than $10 \mathrm{~cm}$. Trees were defined as woody plants with a DBH greater than or equal to $10 \mathrm{~cm}$. Total tree height, stem height (the height of the first main branch) and DBH were measured for all trees in the large parcels. Height and DBH were measured for all saplings in the medium parcels. Ground-cover estimation and counting of individuals were carried out for seedlings and herbaceous vegetation in the small parcels. In total, 26 plots of secondary succession and $\mathbf{1 4}$ plots of mature forest were sampled. The measured parameters were used for separation of different successional vegetation stages and primary forest classes based on canonical discriminant analyses (Lu et al. 2003a).

During fieldwork in August 2002, an IKONOS colour composite (acquired 28 May 2001) was used to support the observation of different successional vegetation stages, coffee plantations, and degraded and cultivated pastures. In August 2003, a Satellite pour l'Observation de la Terre (SPOT) colour composite was used to assist the collection of hundreds of observations over a larger area of approximately $2000 \mathrm{~km}^{2}$. After driving extensively throughout the settlement, field observations provided familiarity with the structure of regrowth stages. Visual estimations of vegetation structure attributes, such as canopy height, allowed the rapid 
determination of the three secondary succession classes defined. The distinction of mature forest classes was based on topographic and moist conditions. Exploratory analysis of remote-sensing imagery and a digital elevation model built from topographic maps in 1:100,000 scale supported the delimitation of such classes in the field. The separation of cultivated and degraded pasture classes was based on grass cover and condition. Every observation and sample plot was registered with a global positioning system (GPS) device to allow further integration with spatial data in geographic information systems (GIS) and image processing systems. The successional vegetation stages, coffee plantations, agroforestry systems, and pastures are mainly located near roads. The collection of georeferenced observations for these classes could be accurately located. Some primary forest sites were identified by visual interpretation of the IKONOS or SPOT colour composites and confirmed by local experts. The collected observations were separated into two groups: one group was used as training samples during the maximum-likelihood classification approach, and another group was used for assessing classification results. The difference between the image acquisition data (i.e. Landsat ETM+ and Radarsat data were acquired in 2001) and field data collection dates (i.e. in 2002 and 2003) were considered when determining vegetation classes, especially different successional stages, agroforestry systems, and pastures, based on land-use history and image interpretation. All sample plots were examined against the Landsat ETM + image to make sure the land-cover classes were correctly assigned.

\subsection{Data preprocessing}

3.3.1 Landsat ETM+ data. Landsat 7 ETM+ data, which were acquired on 11 August 2001, were first geometrically registered to another Landsat TM image (18 June 1998), which was already rectified (Universal Transverse Mercator, south 20 zone). A nearest-neighbour algorithm was used to resample the Landsat ETM+ multispectral image into a pixel size of $30 \mathrm{~m} \times 30 \mathrm{~m}$ and panchromatic image into $15 \mathrm{~m} \times 15 \mathrm{~m}$ during image registration. A root-mean-square error of 0.36 pixels for the registration was obtained. An image-based dark object subtraction model was used to implement radiometric and atmospheric correction (Lu et al. 2002). The surface reflectance values after calibration ranged between 0 and 1. For the convenience of data analysis, the reflectance values were linearly rescaled to 8-bit integer format (0-255).

3.3.2 Radarsat data. The Radarsat C-band, $\mathrm{HH}$ polarization data, which were acquired on 21 September 2001, were used in this research. This image was converted to a backscattering coefficient $(\sigma)$ using the following model (Ribbes and le Toan 1999, Chakraborty and Panigrahy 2000):

$$
\sigma_{j}^{0}=\operatorname{lolog}_{10}\left[\left(D N_{j}^{2}+\alpha\right) / A_{j}\right]+\operatorname{lol}_{10}\left[\sin \left(I_{j}\right)\right]
$$

where $D N_{j}$ is the digital number (amplitude of the backscattered signal), $A_{j}$ is the calibration coefficient (scaling gain value) of the $j_{\text {th }}$ pixel, $\alpha$ is a constant offset, and $I_{j}$ is the incidence angle at the $j$ th range pixel. The backscattered coefficient was then linearly rescaled to 8-bit integer format (0-255).

The Radarsat data were geometrically registered to 2001 Landsat ETM+ data with a root-mean-square error of 0.79 pixels. The image was resampled to a pixel size of $15 \mathrm{~m} \times 15 \mathrm{~m}$ using a nearest-neighbour resampling algorithm. Reducing speckle in the Radarsat image was needed before it could be used for land-cover 
classification. Different filtering approaches have been examined in previous works, such as the enhanced Lee filter, the Lee-Sigma, and the Gamma MAP (Panigrahy et al. 1999, Rio and Lozano-Garcia 2000, Ndi Nyoungui et al. 2002). Here, the enhanced Lee filter was used.

\subsection{Data fusion}

Many methods have been developed to integrate spectral and spatial information. Pohl and Van Genderen (1998) reviewed methods for multisensor data fusion. The intensity-hue-saturation (IHS) transformation is the most frequently used method for improving the visual display of multisensor data (Welch and Ehlers 1987), but this approach can employ only three bands, and the resultant image may be unsuitable for classification. To preserve the spectral integrity of the input dataset, principal component analysis (PCA) is often used for data fusion to produce an output result for further quantitative analysis. Recently, wavelet-merging techniques have emerged as another effective approach to integrate spectral and spatial information contents (Li et al. 2002, Ulfarsson et al. 2003). Therefore, this paper used the wavelet-merging approach to integrate Landsat ETM+ multispectral and panchromatic or Radarsat data.

Wavelet theory is similar to the Fourier transform analysis, but the wavelet transform uses short, discrete wavelets, instead of a long wave as in the Fourier transform. One key step during the wavelet transform is to select the mother wavelet. The input image is broken down into successively smaller multiples of the mother wavelet. The derived wavelets have many mathematically useful characteristics that make them preferable to simple sine or cosine functions. Once the mother wavelet is defined, a family of multiples can be created with incrementally increasing frequency. Then the image can be decomposed by applying coefficients to each waveform. In theory, an image can be decomposed into high-frequency and lowfrequency components. The wavelet family can be regarded as a high-pass filter. The low-frequency image is the lower spatial resolution image and the high-frequency image is the higher spatial resolution image containing the details of the image. In general, the high spatial resolution image is a single band, such as the Landsat ETM+ panchromatic band, so the substitution image from the multispectral image must also be a single band. Thus, PCA is used to convert the multispectral bands into new components. The first component contains most of the information and is used as the substitution image. A detailed description of the wavelet-merging technique is found in Lemeshewsky (1999) and ERDAS Field Guide (2003). In this research, the higher spatial resolution data-Landsat ETM+ panchromatic and Radarsat data - were used to integrate the Landsat ETM+ multispectral data with the wavelet-merging technique in order to incorporate the high spatial resolution information and to preserve the Landsat ETM+ multispectral features in the new, fused image.

\subsection{Texture analysis}

Textures have proven useful in improving land-cover classification accuracy. Many texture measures have been developed (Haralick et al. 1973, Kashyap et al. 1982, Emerson et al. 1999), and used at this scope (Marceau et al. 1990, Augusteijn et al. 1995, Groom et al. 1996, Shaban and Dikshit 2001, Chen et al. 2004). Many previous applications of textures are related to urban studies because of the 
complexity of urban landscapes requiring higher spatial resolution data such as SPOT HRV. For Amazonian land-cover classification, the role of textures has not been extensively explored. The enhanced characteristics of Landsat ETM+ data include a panchromatic band of $15-\mathrm{m}$ spatial resolution, which provides richer textural and contextual information than multispectral bands with $30-\mathrm{m}$ spatial resolution. Use of textures based on the Landsat ETM+ panchromatic band may improve classification accuracy. Also, radar data are often used in texture form. Hence, in our study, texture analysis focused on Landsat ETM+ panchromatic and Radarsat data.

The GLCM-based (grey level co-occurrence matrix) texture measures are often used. In this paper, eight GLCM-based texture measures (i.e. mean [ME], variance [VA], homogeneity [HO], contrast [CO], dissimilarity [DI], entropy [EN], second moment [SM] and correlation [CC]) associated with three window sizes $(9 \times 9$, $15 \times 15$, and $21 \times 21$ ) were explored. The texture images were rescaled to 8 -bit integer format (0-255). The Jeffries-Matusita (J-M) algorithm was used to analyse the separability of land-cover classes based on training sample plots (Mausel et al. 1993, Landgrebe 2003). Pearson's correlation analysis was used to analyse the correlation between the selected textures. The textures with high separability but low correlation coefficients were selected based on the following equation:

$$
\text { Best texture combination (BTC) }=\sum_{i=1}^{n} \mathrm{JM}_{i} / \sum_{j=1}^{n} R_{i j}
$$

where JM is the Jeffries-Matusita distance value based on the training sample plots, $R_{i j}$ is the correlation coefficient between image $i$ and $j$, and $n$ is the number of textural images.

\subsection{Comparative analysis of different image combinations}

Many potential image processing procedures can be used for land-cover classification. Hence, identification of the most suitable procedure to improve classification accuracy has considerable significance. In practice, it is not straightforward to define a suitable procedure for a specific study area. In this paper, we present a comparative analysis of different combinations of spectral features and textures based on Landsat ETM + spectral signatures, GLCM-based textures with Landsat ETM+ panchromatic or Radarsat data, data fusion from Landsat ETM+ multispectral and panchromatic or Radarsat data. Table 1 summarizes the different image combinations used in this research. All images were rescaled to 8-bit integer format (0-255) before being used for image classification.

Training sample plots were examined on the 2001 Landsat ETM+ image. Approximately 12-20 sample plots were selected for each class with a polygon size of 9 to 40 pixels for each plot, depending on the homogeneity of the land-cover patch. The maximum-likelihood classifier (MLC) was used to classify the images with the same training sample plots. A majority filter with a window size of $3 \times 3$ pixels was used to remove the 'salt and pepper' effect in the classified images.

The comparative study of different image combinations is based on the accuracy assessment of the land-cover classification images. A common method for accuracy assessment is through the use of an error matrix. Literature on this methodology describes the meanings of and calculations for overall accuracy $(\mathrm{OA})$, producer's accuracy (PA), user's accuracy (UA) and Kappa coefficient (KA) (Congalton 1991, 
Table 1. Design of image processing routines.

\begin{tabular}{|c|c|}
\hline Code & Description \\
\hline ETM-ALL & $\begin{array}{l}\text { Six ETM + reflective bands with } 30-\mathrm{m} \\
\text { spatial resolution }\end{array}$ \\
\hline ETM-Pan & $\begin{array}{l}\text { A combination of six ETM }+ \text { reflective } \\
\text { bands and one ETM }+ \text { panchromatic } \\
\text { band }\end{array}$ \\
\hline ETM-Pantxt & $\begin{array}{l}\text { A combination of ETM-ALL and three } \\
\text { textures from ETM + panchromatic } \\
\text { band }\end{array}$ \\
\hline ETM-Radartxt & $\begin{array}{l}\text { A combination of ETM-ALL and three } \\
\text { textures from Radarsat C-HH band }\end{array}$ \\
\hline Pan-fusion & $\begin{array}{l}\text { Data fusion based on six reflective } \\
\text { ETM + bands and one ETM + } \\
\text { panchromatic band }\end{array}$ \\
\hline Pan-fusion-Pantxt & $\begin{array}{l}\text { A combination of Pan-fusion and } \\
\text { three textures from one ETM + } \\
\text { panchromatic band }\end{array}$ \\
\hline Pan-fusion-Radartxt & $\begin{array}{l}\text { A combination of Pan-fusion and three } \\
\text { textures from Radarsat } \mathrm{C}-\mathrm{HH} \text { band }\end{array}$ \\
\hline Pan_fusion_PanRadartxt & $\begin{array}{l}\text { A combination of Pan-fusion and three } \\
\text { textures from ETM + panchromatic } \\
\text { band and three textures from } \\
\text { Radarsat C-HH band }\end{array}$ \\
\hline Radar-fusion & $\begin{array}{l}\text { Data fusion based on six ETM+ } \\
\text { reflective bands and one Radarsat } \\
\text { C-HH band }\end{array}$ \\
\hline Radar-fusion-Radartxt & $\begin{array}{l}\text { A combination of Radar-fusion and } \\
\text { three textures from Radarsat } \mathrm{C}-\mathrm{HH} \\
\text { band }\end{array}$ \\
\hline Radar-fusion-Pantxt & $\begin{array}{l}\text { A combination of Radar-fusion and } \\
\text { three textures from ETM + } \\
\text { panchromatic band }\end{array}$ \\
\hline Radar-fusion-PanRadartxt & $\begin{array}{l}\text { A combination of Radar-fusion and } \\
\text { three textures from ETM }+ \\
\text { panchromatic band and three } \\
\text { textures from Radarsat C-HH band }\end{array}$ \\
\hline
\end{tabular}

Smits et al. 1999, Foody 2002). In this paper, test sample plots have been selected using the fieldwork carried out in 2002 and 2003 and visual interpretation of the IKONOS image. A total of 345 sample plots were used for accuracy assessment. An error matrix for each classification image was produced and UA, PA, OA and KA were calculated.

\section{Results}

\subsection{Selection of textures for classification}

Separability analysis reveals the capability of single textures to distinguish landcover classes, and the BTC approach helps to identify the potentially best combination of textures for land-cover classification. The textures with separability values greater than 500 for the Landsat ETM+ panchromatic band and greater than 300 for the Radarsat image were selected (table 2). The correlation coefficients of the selected textures indicate that some textures are highly correlated. For example, the 
Table 2. Comparison of separability among the textures based on the Jeffries-Matusita distance algorithm.

\begin{tabular}{|c|c|c|c|c|c|c|c|c|c|}
\hline \multirow[b]{2}{*}{ Sensor data } & \multirow{2}{*}{$\begin{array}{l}\text { Window } \\
\text { size }(\mathrm{m})\end{array}$} & \multicolumn{8}{|c|}{ Separability based on single texture } \\
\hline & & ME & VA & HO & $\mathrm{CO}$ & DI & EN & SM & $\mathrm{CC}$ \\
\hline \multirow{4}{*}{$\begin{array}{l}\text { Landsat ETM+ } \\
\text { panchromatic band }\end{array}$} & $9 \times 9$ & 1056 & 350 & 398 & 372 & 381 & 459 & 486 & 406 \\
\hline & $15 \times 15$ & 1032 & 515 & 480 & 478 & 487 & 481 & 551 & 488 \\
\hline & $21 \times 21$ & 984 & 562 & 509 & 497 & 524 & 507 & 578 & 503 \\
\hline & $9 \times 9$ & 708 & 285 & 188 & 319 & 228 & 161 & 135 & 284 \\
\hline \multirow[t]{2}{*}{ Radarsat } & $15 \times 15$ & 782 & 359 & 269 & 347 & 286 & 277 & 249 & 335 \\
\hline & $21 \times 21$ & 812 & 460 & 298 & 377 & 317 & 324 & 276 & 401 \\
\hline
\end{tabular}

ME, mean; VA, variance; HO, homogeneity; CO, contrast; DI, dissimilarity; EN, entropy; $\mathrm{SM}$, second moment; $\mathrm{CC}$, correlation.

correlation coefficients are $0.96,-0.92$ and -0.90 , respectively, between textural images based on contrast (CO) and dissimilarity (DI), homogeneity (HO) and DI, and entropy (EN) and second moment (SM) from the Landsat ETM+ panchromatic band. The textural images with high correlation coefficients have similar information contents. Therefore, the selection of textures with high separability values but low correlation coefficients between them is important. The analysis of best texture combinations (BTC) indicates that the best three textures are mean (ME) with a $15 \times 15$ window and variance (VA) and SM with a $21 \times 21$ window based on panchromatic band, and ME, VA and CO with a $21 \times 21$ window based on the Radarsat $\mathrm{C}-\mathrm{HH}$ band. These textures were combined with Landsat ETM+ spectral images for classification.

\subsection{Comparison of classification accuracies}

This research indicates the difficulty of using remotely sensed data for land-cover (especially vegetation) classification in moist tropical regions. Table 3 summarizes the classification accuracies of different image combinations. Overall, nonvegetation classes (i.e. infrastructure [INF], water [WAT] and non-vegetation lowland [NVL]) have higher classification accuracies than vegetation classes (e.g. primary forest, secondary succession, pastures), and primary forest (e.g. upland forest [UPF] and lowland forest [LLF]) has higher accuracy than different secondary successional stages. The classification accuracies of intermediate and advanced successions (SS2 and SS3), agroforestry (AGF) and degraded pasture (DGP) are especially poor because of the similar spectral features between SS2, SS3 and AGF and between DGP and initial succession (SSI). The six Landsat ETM+ spectral bands (ETM-ALL) and the combination of six spectral bands and one panchromatic band (ETM-Pan) produced similar classification accuracies, except for SS2, which slightly improved accuracy, and AGF, which slightly decreased accuracy in ETM-Pan. The combination of textures from the panchromatic band (ETM-Pantxt) slightly improved classification accuracy compared to ETM-ALL, but the overall classification accuracy from the combination of textures from Radarsat data (ETMRadartxt) slightly decreased. The overall classification accuracy from the data fusion images (based on either Landsat ETM+ multispectral and panchromatic data (Pan-fusion) or Landsat ETM+ multispectral and Radarsat data [Radarfusion]) slightly decreased compared to the original ETM-ALL data. However, the incorporation of data fusion with textures from higher spatial resolution 
Table 3. A comparison of different combinations of Landsat ETM+ spectral features and textures.

\begin{tabular}{|c|c|c|c|c|c|c|c|c|}
\hline \multirow[b]{2}{*}{ Type } & \multicolumn{2}{|c|}{ ETM-ALL } & \multicolumn{2}{|c|}{ ETM-Pan } & \multicolumn{2}{|c|}{ ETM-Pantxt } & \multicolumn{2}{|c|}{ ETM-Radartxt } \\
\hline & PA\% & UA $\%$ & $\mathbf{P A} \%$ & UA $\%$ & $\mathbf{P A} \%$ & UA\% & PA\% & UA\% \\
\hline UPF & 73.08 & 95.00 & 73.08 & 90.48 & 80.77 & 91.30 & 73.08 & 86.36 \\
\hline LLF & 84.62 & 64.71 & 84.62 & 64.71 & 92.31 & 75.00 & 84.62 & 64.71 \\
\hline SS3 & 46.15 & 18.18 & 46.15 & 18.75 & 84.62 & 27.50 & 46.15 & 18.75 \\
\hline SS2 & 21.43 & 45.00 & 23.81 & 47.62 & 21.43 & 52.94 & 14.29 & 35.29 \\
\hline SS1 & 64.62 & 63.64 & 64.62 & 63.64 & 61.54 & 63.49 & 61.54 & 59.70 \\
\hline DGP & 48.65 & 66.67 & 45.95 & 65.38 & 48.65 & 58.06 & 48.65 & 54.55 \\
\hline CUP & 90.91 & 94.34 & 90.91 & 94.34 & 96.36 & 94.64 & 89.09 & 92.45 \\
\hline AGF & 62.50 & 37.04 & 59.38 & 35.85 & 46.88 & 40.54 & 59.38 & 42.22 \\
\hline CFP & 66.10 & 73.58 & 67.8 & 74.07 & 72.88 & 71.67 & 67.80 & 71.43 \\
\hline INF & 90.91 & 100.00 & 90.91 & 100 & 90.91 & 100.00 & 90.91 & 90.91 \\
\hline WAT & 100.00 & 84.62 & 100 & 84.62 & 100.00 & 78.57 & 100.00 & 78.57 \\
\hline NVL & 83.33 & 100.00 & 83.33 & 100 & 75.00 & 100.00 & 75.00 & 100.00 \\
\hline OA & \multirow{2}{*}{\multicolumn{2}{|c|}{$\begin{array}{c}65.16 \\
0.6089\end{array}$}} & \multicolumn{2}{|c|}{65.16} & \multicolumn{2}{|c|}{67.02} & \multicolumn{2}{|c|}{63.30} \\
\hline \multirow[t]{2}{*}{ KA } & & & \multicolumn{2}{|c|}{0.6087} & \multicolumn{2}{|c|}{0.6297} & \multicolumn{2}{|c|}{0.5877} \\
\hline & \multicolumn{2}{|c|}{ Pan-fusion } & \multicolumn{2}{|c|}{ Pan-fusion-Pantxt } & \multicolumn{2}{|c|}{$\begin{array}{l}\text { Pan-fusion- } \\
\text { Radartxt }\end{array}$} & \multicolumn{2}{|c|}{$\begin{array}{l}\text { Pan-fusion- } \\
\text { PanRadartxt }\end{array}$} \\
\hline Type & $\mathbf{P A} \%$ & UA\% & $\mathbf{P A} \%$ & UA\% & $\mathbf{P A} \%$ & UA\% & PA\% & UA\% \\
\hline UPF & 76.92 & 90.91 & 80.77 & 87.50 & 84.62 & 84.62 & 80.77 & 95.45 \\
\hline LLF & 84.62 & 61.11 & 92.31 & 66.67 & 84.62 & 68.75 & 100.00 & 72.22 \\
\hline SS3 & 69.23 & 22.50 & 84.62 & 32.35 & 46.15 & 23.08 & 69.23 & 40.91 \\
\hline SS2 & 21.43 & 36.00 & 23.81 & 52.63 & 19.05 & 53.33 & 16.67 & 70.00 \\
\hline SS1 & 53.85 & 61.40 & 63.08 & 62.12 & 70.77 & 62.16 & 81.54 & 59.55 \\
\hline DGP & 40.54 & 53.57 & 45.95 & 58.62 & 45.95 & 54.84 & 40.54 & 60.00 \\
\hline CUP & 89.09 & 94.23 & 96.36 & 94.64 & 92.73 & 92.73 & 98.18 & 91.53 \\
\hline $\mathrm{AGF}$ & 53.13 & 34.00 & 43.75 & 34.15 & 50.00 & 42.11 & 43.75 & 58.33 \\
\hline CFP & 57.63 & 68.00 & 66.10 & 69.64 & 74.58 & 70.97 & 86.44 & 68.92 \\
\hline INF & 90.91 & 90.91 & 90.91 & 100.00 & 90.91 & 100.00 & 90.91 & 100.00 \\
\hline WAT & 100.00 & 78.57 & 100.00 & 78.57 & 100.00 & 73.33 & 100.00 & 78.57 \\
\hline NVL & 75.00 & 100.00 & 75.00 & 100.00 & 66.67 & 100.00 & 75.00 & 100.00 \\
\hline $\mathrm{OA}$ & \multicolumn{2}{|c|}{60.90} & \multicolumn{2}{|c|}{65.96} & \multicolumn{2}{|c|}{66.49} & \multicolumn{2}{|c|}{71.01} \\
\hline KA & \multicolumn{2}{|c|}{0.5629} & \multicolumn{2}{|c|}{0.6176} & \multicolumn{2}{|c|}{0.6219} & \multicolumn{2}{|c|}{0.6706} \\
\hline
\end{tabular}

images - Landsat ETM + panchromatic or Radarsat data - is helpful in improving classification accuracies. In particular, the combination of data fusion and textures from both panchromatic and Radarsat data improved overall accuracies by $5.8 \%$ to $6.9 \%$ if compared to ETM-ALL.

\section{Discussion and conclusion}

Vegetation classification in the moist tropical region, especially of land-cover types like SS2 and SS3, is very difficult, but the use of textures is an effective approach for improvement. Indeed, a combination of textures and image data fusion generally improved classification accuracy by approximately $5.8-6.9 \%$ when compared to using the original Landsat ETM + spectral images. On the contrary, the data fusion based on Landsat ETM + multispectral and panchromatic data or Radarsat data did not effectively improve classification accuracies. 
Table 3. (Continued)

\begin{tabular}{|c|c|c|c|c|c|c|c|c|}
\hline \multirow[b]{2}{*}{ Type } & \multicolumn{2}{|c|}{ Radar-fusion } & \multicolumn{2}{|c|}{$\begin{array}{c}\text { Radar-fusion- } \\
\text { Radartxt }\end{array}$} & \multicolumn{2}{|c|}{$\begin{array}{c}\text { Radar-fusion- } \\
\text { Pantxt }\end{array}$} & \multicolumn{2}{|c|}{$\begin{array}{l}\text { Radar-fusion- } \\
\text { PanRadartxt }\end{array}$} \\
\hline & $\mathbf{P A} \%$ & UA\% & $\mathbf{P A} \%$ & UA\% & $\mathbf{P A} \%$ & UA $\%$ & $\mathbf{P A} \%$ & UA $\%$ \\
\hline UPF & 84.62 & 95.65 & 84.62 & 88.00 & 80.77 & 95.45 & 80.77 & $\mathbf{9 5 . 4 5}$ \\
\hline LLF & 92.31 & 80.00 & 84.62 & 68.75 & 92.31 & 70.59 & 100.00 & 72.22 \\
\hline SS3 & 76.92 & 25.64 & 61.54 & 26.67 & 84.62 & 31.43 & 61.54 & 44.44 \\
\hline SS2 & 26.19 & 47.83 & 16.67 & 43.75 & 21.43 & 52.94 & 16.67 & 63.64 \\
\hline SSI & 55.38 & 61.02 & 69.23 & 62.50 & 63.08 & 60.29 & 89.23 & 63.04 \\
\hline DGP & 45.95 & 58.62 & 43.24 & 50.00 & 43.24 & 64.00 & 37.84 & 58.33 \\
\hline CUP & 90.91 & 96.15 & 90.91 & 92.59 & 98.18 & 94.74 & 98.18 & 91.53 \\
\hline $\mathrm{AGF}$ & 56.25 & 36.00 & 56.25 & 51.43 & 50.00 & 38.10 & 46.88 & 55.56 \\
\hline CFP & 62.71 & 71.15 & 77.97 & 73.02 & 69.49 & 68.33 & 86.44 & 70.83 \\
\hline INF & 90.91 & 90.91 & 90.91 & 100.00 & 90.91 & 100.00 & 90.91 & 100.00 \\
\hline WAT & 100.00 & 78.57 & 100.00 & 73.33 & 100.00 & 78.57 & 100.00 & 78.57 \\
\hline NVL & 75.00 & 100.00 & 66.67 & 100.00 & 75.00 & 100.00 & 75.00 & 100.00 \\
\hline $\mathrm{OA}$ & \multicolumn{2}{|c|}{64.63} & \multicolumn{2}{|c|}{67.02} & \multicolumn{2}{|c|}{66.76} & \multicolumn{2}{|c|}{72.07} \\
\hline $\mathbf{K A}$ & \multicolumn{2}{|c|}{0.6040} & \multicolumn{2}{|c|}{0.6282} & \multicolumn{2}{|c|}{0.6260} & \multicolumn{2}{|c|}{0.6823} \\
\hline
\end{tabular}

PA, producer's accuracy; UA, user's accuracy, OA, overall accuracy, KA, kappa coefficient. UPF, upland forest; LLF, lowland forest; SS3, advanced successional vegetation; SS2, intermediate successional vegetation; SSI, initial successional vegetation; DGP, degraded pasture; CUP, cultivated pasture; AGF, agroforestry; CFP, coffee plantation; INF, infrastructure; WAT, water; NVL, non-vegetation lowland.

The complex forest stand structures and abundant tree species may be the most important factors inducing difficulty of vegetation classification in the Amazon. For example, the smooth transition between stages of successional vegetations and the spectral confusion between successional vegetations and agroforestry makes their classification accuracies poor. Agroforestry is a complex category, including a variety of productive arrangements based on the association of two or more species. Another problem is the difficulty in collecting sufficient training and test samples for some vegetation classes, especially for successional stages. In this study area, the lack of typical SS3 samples is an important factor resulting in poor SS3 classification accuracy. The selected SS3 samples are mainly in younger stages of SS3 and are often confused with old SS2 vegetation because of their similar vegetation stand structure.

This research has shown that texture measures represent an important factor in improving land-cover classification accuracies. One critical step is to identify suitable textures that provide the best separability for the land-cover classes. However, selection of suitable textures is a challenge because textures vary with the characteristics of the landscape under investigation and images used. Identifying suitable textures involves the selection of appropriate texture measures, moving window sizes, and image bands (Franklin et al. 1996, Chen et al. 2004). Not all texture measures can improve classification performance. Even for the same texture measure, selecting the appropriate window size and spectral band is crucial. The BTC approach provides an easy way to identify the best combination of textures to improve classification performance based on the separability of land-cover classes and correlation coefficients between the selected textures.

The data fusion image enhanced visual interpretation through the incorporation of high spatial resolution information in the fused dataset. However, data fusion may decrease classification accuracy, especially for the vegetation types with lack of 
obvious stand structures, such as SS1 and DGP in this study. The major reason may be that data fusion increases the variation within the same vegetation class. On the contrary, textures make use of the spatial information inherent in the image and reduce the spectral variation. Thus, use of data fusion and texture benefits the landcover classification.

\section{Acknowledgments}

The authors wish to thank the National Science Foundation (grant no. 95-21918 and no. 99-06826), the National Aeronautics and Space Administration (grant no. NCC5-695), and Brazil's Embrapa Satellite Monitoring for their support. This project is part of the Large-Scale Biosphere Atmosphere Experiment in Amazônia (LBA) Program, LC-34, which aims to examine the human and physical dimensions of land-cover change.

\section{References}

AdAMS, J.B., SABOL, D.E., Kapos, V., Fllho, R.A., ROBERTS, D.A., SMith, M.O. and GLLESPE, A.R., 1995, Classification of multispectral images based on fractions of endmembers: application to land-cover change in the Brazilian Amazon. Remote Sensing of Environment, 52, pp. 137-154.

AtKinson, P.M. and TAtnal, A.R.L., 1997, Neural networks in remote sensing. International Joumal of Remote Sensing, 18, pp. 699-709.

Augusteun, M.F., Clemens, L.E. and Shaw, K.A., 1995, Performance evaluation of texture measures for ground cover identification in satellite images by means of a neural network classifier. IEEE Transactions on Geoscience and Remote Sensing, 33, pp. 616-625.

BAtistell., M., 2001, Landscape change and land-use/land-cover dynamics in Rondônia, Brazilian Amazon. PhD dissertation, Indiana University, Bloomington, IN, $399 \mathrm{pp}$.

Batistell.A, M. and Moran, E.F., 2005, Dimensões humanas do uso e cobertura das terras na Amazônia: uma contribuição do LBA. Acta Amazonica, 35, pp. 239-247.

Batistella, M., Robeson, S. and Moran, E.F., 2003, Settlement design, forest fragmentation, and landscape change in Rondônia, Amazônia. Photogrammetric Engineering and Remote Sensing, 69, pp. 805-812.

Brondizio, E.S., Moran, E.F., MAuSel, P. and Wu, Y., 1996, Land cover in the Amazon estuary: linking of the Thematic Mapper with botanical and historical data. Photogrammetric Engineering and Remote Sensing, 62, pp. 921-929.

Chakraborty, M. and Panigrahy, S., 2000, A processing and software system for rice crop inventory using multi-date RADARSAT ScanSAR data. ISPRS Journal of Photogrammetry and Remote Sensing, 55, pp. 119-128.

Chen, D., Stow, D.A. and Gong, P., 2004, Examining the effect of spatial resolution and texture window size on classification accuracy: an urban environment case. International Journal of Remote Sensing, 25, pp. 2177-2192.

Congalton, R.G., 1991, A review of assessing the accuracy of classification of remotely sensed data. Remote Sensing of Ewvironment, 37, pp. 35-46.

Emerson, C.W., LAM, N.S. and QuATrRoch, D.A., 1999, Multi-scale fractal analysis of image texture and pattern. Photogrammetric Engineering and Remote Sensing, 65, pp. 51-61.

ERDAS Field Guide (7th edn), 2003, Leica Geosystems GIS \& Mapping, LLC, Atlanta, GA, USA.

FOODY, G.M., 2002, Status of land cover classification accuracy assessment. Remote Sensing of Environment, 80, pp. 185-201.

Foody, G.M., PAlubinskas, G., LuCAs, R.M., CurRan, P.J. and HonZÁK, M., 1996, Identifying terrestrial carbon sinks: classification of successional stages in regenerating 
tropical forest from Landsat TM data. Remote Sensing of Environment, 55, pp. 205-216.

Franklin, S.E., Wulder, M.A. and LAvigne, M.B., 1996, Automated derivation of geographic window sizes for remote sensing digital image texture analysis. Computers and Geosciences, 22, pp. 665-673.

FriedL, M.A. and BroDley, C.E., 1997, Decision tree classification of land cover from remotely sensed data. Remote Sensing of Environment, 61, pp. 399-409.

GroOm, G.B., FUller, R.M. and Jones, A.R., 1996, Contextual correction: techniques for improving land cover mapping from remotely sensed images. International Journal of Remote Sensing, 17, pp. 69-89.

Haralick, R.M., Shanmugam, K. and Dinstein, I., 1973, Textural features for image classification. IEEE Transactions on Systems, Man and Cybernetics, 3, pp. 610-620.

INPE (Instituto Nacional de Pesquisas Espaciais) 2002, Monitoring of the Brazilian Amazon Forest by Satellite 2000-2001, INPE, São José dos Campos, SP, Brazil, 23 p.

Kashyap, R.L., Chellappa, R. and Khotanzad, A., 1982, Texture classification using features derived from random field models. Pattern Recognition Letters, 1, pp. 43-50.

Kavzoglu, T. and Mather, P.M., 2004, The use of backpropagating artificial neural networks in land cover classification. International Journal of Remote Sensing, 24, pp. $4907-4938$.

LANDGreBe, D.A., 2003, Signal Theory Methods in Multispectral Remote Sensing (Hoboken, NJ: John Wiley and Sons).

LEMESHEWSKY, G.P., 1999, Multispectral multisensor image fusion using wavelet transforms. Proceedings of SPIE, 3716, pp. 214-222.

LI, S., KWOK, J.T. and WANG, Y., 2002, Using the discrete wavelet frame transform to merge Landsat TM and SPOT panchromatic images. Information Fusion, 3, pp. 17-23.

LU, D., 2005, Integration of vegetation inventory data and Landsat TM image for vegetation classification in the western Brazilian Amazon. Forest Ecology and Management, 213, pp. 369-383.

Lu, D., Mausel, P., Brondizio, E. and Moran, E., 2002, Assessment of atmospheric correction methods for Landsat TM data applicable to Amazon basin LBA research. International Journal of Remote Sensing, 23, pp. 2651-2671.

Lu, D., Mausel, P., Brondízio, E. and Moran, E., 2003a, Classification of successional forest stages in the Brazilian Amazon basin. Forest Ecology and Management, 181, pp. 301-312.

Lu, D., Moran, E. and BATistella, M., 2003b, Linear mixture model applied to Amazônian vegetation classification. Remote Sensing of Environment, 87, pp. 456-469.

Lu, D., Mausel, P., Batistella, M. and Moran, E., 2004, Comparison of land-cover classification methods in the Brazilian Amazon basin. Photogrammetric Engineering and Remote Sensing, 70, pp. 723-731.

Lucas, R.M., Honzak, M., do Amaral, I., Curran, P.J. and Foody, G.M., 2002, Forest regeneration on abandoned clearances in central Amazonia. International Journal of Remote Sensing, 23, pp. 965-988.

MarCEaU, D.J., HowarTh, P.J., Dubois, J.M. and Gratton, D.J., 1990, Evaluation of the grey-level co-occurrence matrix method for land-cover classification using SPOT imagery. IEEE Transactions on Geoscience and Remote Sensing, 28, pp. 513-519.

MAusel, P., Wu, Y., Li, Y., Moran, E.F. and Brondizio, E.S., 1993, Spectral identification of succession stages following deforestation in the Amazon. Geocarto International, 8 , pp. 61-72.

Moran, E.F., Brondízio, E.S. and Mausel, P., 1994, Secondary succession. Research and Exploration, 10, pp. 458-476.

Ndi Nyoungui, A., Tonye, E. and Akono, A., 2002, Evaluation of speckle filtering and texture analysis methods for land cover classification from SAR images. International Journal of Remote Sensing, 23, pp. 1895-1925. 
PAL, M. and MATher, P.M., 2003, An assessment of the effectiveness of decision tree methods for land cover classification. Remote Sensing of Environment, 86, pp. 554-565.

Panigrahy, S., Manunath, K.R., Chakraborty, M., Kundu, N. and Paruhar, J.S., 1999, Evaluation of RADARSAT standard beam data for identification of potato and rice crops in India. ISPRS Journal of Photogrammetry and Remote Sensing, 54, pp. 254-262.

PAOLA, J.D. and SChOWEnGERDT, R.A., 1995, A review and analysis of back propagation neural networks for classification of remotely sensed multispectral imagery. International Journal of Remote Sensing, 16, pp. 3033-3058.

POHL, C. and VAN GENDEREN, I.L., 1998, Multisensor image fusion in remote sensing: concepts, methods, and applications. International Joumal of Remote Sensing, 19 , pp. 823-854.

RıBBES, F. and LE TOAN, T., 1999, Rice field mapping and monitoring with RADARSAT data. International Journal of Remote Sensing, 20, pp. 745-765.

Rıgnot, E., SAlAS, W.A. and SkOLE, D.L., 1997, Mapping deforestation and secondary growth in Rondônia, Brazil, using imaging radar and Thematic Mapper data. Remote Sensing of Environment, 59, pp. 167-179.

RıO, J.N.R. and LOZANO-GARCIA, D.F., 2000, Spatial filtering of Radar data (RADARSAT) for wetlands (Brackish Marshes) classification. Remote Sensing of Environment, 73, pp. 143-151.

Roberts, D.A., Batista, G.T., Pereira, J.L.G., WAller, E.K. and Nelson, B.W., 1998, Change identification using multitemporal spectral mixture analysis: applications in eastern Amazônia. In Remote Sensing Change Detection: Environmental monitoring methods and applications, R.S. Lunetta and C.D. Elvidge (Eds), pp. 137-161 (Ann Arbor, MI: Ann Arbor Press).

RoNDÔNIA, 1998, Diagnóstico sócio-econômico do Estado de Rondônia e assistência técrica para formulação da segunda aproximação do zoneamento sócio-econômico-ecológico Climatologia, v.l. Governo de Rondônia/PLANAFLORO, Porto Velho, Brasil.

ShaBAN, M.A. and Diksurr, O., 2001, Improvement of classification in urban areas by the use of textural features: the case study of Lucknow city, Uttar Pradesh. International Journal of Remote Sensing, 22, pp. 565-593.

Smits, P.C., Dellepiane, S.G. and Schowengerdt, R.A., 1999, Quality assessment of image classification algorithms for land-cover mapping: a review and a proposal for a costbased approach. International Joumal of Remote Sensing, 20, pp. 1461-1486.

STEININGER, M.K., 1996, Tropical secondary forest regrowth in the Amazon: age, area and change estimation with Thematic Mapper data. International Journal of Remote Sensing, 17, pp. 9-27.

UlfarsSON, M.O., BenEDIKTSSON, J.A. and Sveinsson, J.R., 2003, Data fusion and feature extraction in the wavelet domain. International Journal of Remote Sensing, 24, pp. 3933-3945.

Vieira, I.C.G., De Almeida, A.S., Davidson, E.A., Stone, T.A., De Carvalho, C.J.R. and Guerrero, J.B., 2003, Classifying successional forests using Landsat spectral properties and ecological characteristics in eastern Amazonia. Remote Sensing of Environment, 87, pp. $470-481$.

WeLCH, R. and EHLERS, M., 1987, Merging multi-resolution SPOT HRV and Landsat TM data. Photogrammetric Engineering and Remote Sensing, 53, pp. 301-303.

Yanasse, C.C.F., SAnt'Anna, S.J.S., Frery, A.C., Rennó, C.D., Soares, J.V. and LUCKMAN, A.J., 1997, Exploratory study of the relationship between tropical forest regeneration stages and SIR-C L and C data. Remote Sensing of Environment, 59, pp. $180-190$. 